\title{
DIFFICILE EST PROPRIE COMMUNIA DICERE: EL GÉNERO DE LA NOVELLA ENTRE BOCCACCIO Y CERVANTES
}

\author{
Antonio Gargano \\ Università degli Studi di Napoli Federico II \\ antgarga@unina.it
}

$\longrightarrow$

elebérrimas son las palabras con las que, dirigiéndose al «lector amable», Cervantes reivindica para sí el mérito de la prioridad y de la originalidad en el género que nos ocupa:

yo soy el primero que ha novelado en lengua castellana, que las muchas novelas que en ella andan impresas, todas son traducidas de lenguas extranjeras, y éstas son mías propias, no imitadas ni hurtadas; mi ingenio las engendró, y las parió mi pluma, y van creciendo en los brazos de la estampa. (Cervantes 2001: 19)

Novela y novelar aparecen entre los vocablos de la lengua italiana que Juan de Valdés, en el Diálogo de la lengua, dice querer «aprovechar para la lengua castellana» (Valdés 1982: 222). De modo que no hay ninguna duda de que Cervantes, en el citado pasaje del prólogo, hace referencia al afortunado género narrativo de la novela italiana, el cual, en el siglo XVI, a partir de la tardía traducción del siglo XV del Decamerón (1496) ${ }^{1}$, había conocido una amplia difusión en la península ibérica, como atestiguan las versiones de las colecciones de novelas de Straparola, de Guicciardini con las Hore di ricreatione, de Bandello y de Giraldi Cinthio, publicadas todas en el breve espacio de menos de una década, que va de 1583 a $1592^{2}$.

Puesto que al atribuirse el papel de inventor del género novelístico Cervantes dice sustancialmente la verdad, su colección goza, por así decir, de un doble

1 En efecto, existe una versión castellana del Decamerón más antigua, conservada en el ms. J-II-21 de la Biblioteca del Real Monasterio de San Lorenzo del Escorial, recientemente publicada por Valvassori (2009). Sobre la tradición hispánica del Decamerón boccacciano, véase la reciente y exaustiva reseña de Valero Moreno (2010).

2 Sobre las traducciones de las mencionadas recopilaciones de novelas italianas, véanse, al menos, Amezúa y Mayo (1956: I, 440-465) y el breve capítulo de Laspéras (1987: 56-71). 
privilegio: al inaugurar en lengua española el género narrativo italiano, marca con ella también — como a menudo ha sido reconocido- el límite en la historia de la novela corta europea, la llamada 'clásica', a partir del cual el género queda privado de sus «costituzionali convenzioni compositive» (Brangantini 1987: 39). Y no se trata de una mera línea terminal o divisoria, ya que lo que está en juego con la obra cervantina respecto al modelo boccacciano, a propósito del cual todavía en 1574 la única voz teórica sobre el género — la de Francesco Bonciani- sentenciaba que «i concetti e precetti del novellare si ritruovano in Boccacio» ${ }^{4}$ (Bonciani 1972: 137-138); con respecto al modelo boccacciano — decía— el libro cervantino constituye una auténtica recodificación del género, de la que quisiera ilustrar algún aspecto en el espacio que generosamente me ha sido concedido. Naturalmente, soy muy consciente de que la decisión de no tener en cuenta — salvo en alguna mención más adelante- el siglo xvI, o sea, el siglo que está considerado con razón «di massima proliferazione della forma novellistica», quita al menos en parte — si no totalmente - credibilidad a lo que me predispongo a exponer. Así pues, al ser la novela un género «a codificazione debole», el «nomadismo formale della novella del Cinquecento», como sintéticamente ha sido definida por Bragantini la indiscriminada variedad a la que dio lugar «lo sforzo di caratterizzazione individuale che costituisce uno dei contrassegni della tradizione novellistica a partire dall'archetipo boccacciano» (Bragantini 2000: 37, 57, 44, 57); ese nomadismo quinientista, en fin, nos llevaría a entrar en un laberinto de soluciones, del que no sería fácil encontrar la salida con la necesaria prontitud.

Al prólogo de la colección cervantina tendremos que volver pronto, después de haber tomado en consideración otra reivindicación de prioridad y de originalidad, siempre relativa al género novelístico, pero en versos esta vez, contenida en un terceto del Viaje del Parnaso (1614) y compuesta, probablemente, en el periodo de la redacción del célebre prólogo —en la primera mitad de 1612. En el acto de presentar sus credenciales al dios de la poesía, entre los diferentes méritos de «raro inventor» que se atribuye, Cervantes no elude una orgullosa referencia a la colección de novelas, a las que alude en los siguiente términos:

Yo he abierto en mis Novelas un camino

por do la lengua castellana puede

mostrar con propiedad un desatino.

(Cervantes 1983: IV, 25-27, p. 254)

Véase también Olsen (1976: 51).

4 La Lezione de Bonciani, en el texto crítico editado por Weinberg, ha sido reproducida en Ordine (2001: 115-181; la cita es de la p. 120). Sobre el tratado de Bonciani, véase Vega Ramos (1993: 70-95), donde la autora ofrece también el texto de la Lezione en la versión española (97-143). 
Para comprender plenamente el significado de esta declaración, en la que Cervantes condensa nada menos que su teoría de la novela, es indispendable no sólo leerla dentro del contexto de su misma obra literaria, como intentaré hacer, sino que resulta muy útil incluso considerarla preliminarmente en relación con la pasada reflexión teórica sobre la poesía, tarea bastante larga y compleja, si no estuviera dispuesto a ejercerla reduciéndola a sus términos esenciales, con un acto de simplificación para el que me será necesario toda la indulgencia de quien esto lee. Ahora bien, al considerar el último verso del terceto de Cervantes, no hay duda — creo — de que vendrá a la mente el que, según uno de sus modernos exégetas, es «uno de los más difíciles [versos] de la literatura latina» (Brink 1971: 204), el v. 128 de la Ars poetica horaciana que fue, por otro lado, objeto de debate por parte de numerosos tratadistas renacentistas: «difficile est proprie communia dicere» (Horace 1989) ${ }^{5}$. Con ese verso el autor latino se dirige al potencial escritor de teatro y le insinúa que los communia - los temas comunes- o, como se dice unos pocos versos más adelante: ignota indictaque —o sea, los temas nuevos y nunca tratados literariamente, claro está-; en suma, esos temas para los que, al no participar de la tradición literaria, no existen en consecuencia las convenciones con las que sea posible forjarlos; tales temas - asevera, pues, Horacio- difícilmente pueden ser acogidos y tratados por parte del escritor proprie, es decir, 'apropiándose de ellos', en el sentido - por supuesto- de hacer de ellos objeto de poesía según las reglas y las convenciones de la tradición literaria. Mejor, por eso, «Iliacum carmen deducere in actus»: o sea, escoger como objeto de la obra —en este caso, la teatral — los temas y los personajes que gozan de una larga tradición literaria, aquí encarnada por el poema homérico.

Más de trece siglos después, volvemos a encontrar el término communia en un pasaje de las Genealogie deorum gentilium de Boccaccio, sobre el que muy oportunamente ha llamado la atención Lucia Battaglia Ricci, reconociendo en él «un'idea della letteratura che non è immeditamente e completamente riducibile alla teoria esposta nelle Genealogie», y poniéndolo, en cambio, en relación con las «forme di rappresentazione "realistiche” legittimate dal genere [della novella] prescelto» (Battaglia Ricci 2008: 194-195) en el Decamerón:

$5 \quad$ Sobre el difícil pasaje, véase el comentario a los versos 128-130 de Rudd en Horace (1989: 171) y Brink (1971: 432 y ss.), donde el estudioso presenta con mucho detalle las diversas interpretaciones del pasaje a partir de los primeros comentarios sobre el Ars Poetica horaciana. Entre finales del s. XVI y principios del XVII, el Ars Poetica conoció en España tres versiones castellanas: la de Vicente Espinel (1591), la de Luis Zapata (1592) y la de Tamayo de Vargas (principios del xvII). Sobre ellas véanse Menéndez Pelayo (1951: VI, 76 y ss.); García Berrio (1980: 113-118; pero, más en general, sobre la presencia e influencia del Ars horaciana entre 1580 y 1617, véanse los capítulos II y III de este mismo libro); Talavera Esteso (1979: 69-101); Alemán Illán (1997: 117-148); y Alemán Illán (1998: 5-22). 
Species vero tercia potius hystorie quam fabule similis est. Hac aliter et aliter usi poete celebres sunt. Nam heroici, quantumcunque videantur hystoriam scribere, ut Virgilius, dum Eneam tempestate maris agitatum scribit, et Homerus alligatum malo navis Ulixem, ne a Syrenarum cantu traheretur, longe tamen aliud sub velamine sentiunt quam monstretur. Comici insuper honestiores, ut Plautus atque Terrentius, hac confabulandi specie etiam usi sunt, nil aliud preter quod lictera sonat intelligentes, volentes tamen arte sua diversorum hominum mores et verba describere, et interim lectores docere et cautos facere. Et hec si de facto non fuerint, cum communia sint esse potuere vel possent (Boccaccio 1998: XIV IX 7).

La tercera especie se asemeja más bien a la historia que a la fábula. Ésta la han usado los poetas famosos de diferentes maneras. Es por eso que los poetas épicos, aunque parezca que escriben una historia, como Virgilio cuando describe a Eneas agitado por la tempestad, y Homero cuando representa a Ulises amarrado al mástil de la nave para no ser atraído por el canto de las sirenas, tienen otra intención bien diferente, bajo el velo de la letra, de lo que muestran. Además, los más honrados cómicos, como Plauto y Terencio, también han usado esta especie de fábula, no pretendiendo más que lo que la letra expresa, queriendo, no obstante, describir, con su arte, las costumbres y las palabras de hombres diversos y entretanto instruir a los lectores y hacerlos cautos. Y estos hechos, si en realidad no sucedieron, pudieron o podrían suceder, pues son comunes.

En el pasaje en cuestión, communia ya no son los argumentos ajenos a la tradición literaria, sino más bien aquellos hechos o asuntos que «si de facto non fuerint [...] esse potuere vel possent». Definidos así, hechos y asuntos 'comunes' sostiene Boccaccio- pueden penetrar en los poemas épicos, como en Homero o Virgilio, ya que son rescatados del significado alegórico que el género les confiere («longe tamen aliud sub velamine sentiunt quam monstretur»), o bien entran en el género cómico de la comedia, como en Plauto o Terencio, donde, sin embargo, no tienen otro significado que el literal, puesto que pretenden «describir, con su arte, las costumbres y las palabras de hombres diversos y entretanto instruir a los lectores haciéndolos cautos» («volentes tamen arte sua diversorum hominum mores et verba describere, et interim lectores docere et cautos facere»). Ahora bien, creo que todos recordarán cómo, en la conclusión del capítulo sobre Boccaccio en su obra maestra, Auerbach niega valor problemático y carácter trágico a las novelas del Decamerón, incluso a «los cuentos que tienden a lo trágico», puesto que — sostiene el genial filólogo — «su [el de Boccaccio] realismo libre, rico y maestro en el dominio de los sucesos, perfectamente natural dentro de los límites del estilo medio, se vuelve fofo y superficial en cuanto roza la problemática o la tragedia» ${ }^{6}$ (1975: 218-219). Pues bien, creo que las dos afirmaciones terminan por

6 Por lo demás, en el último trabajo que vio la luz antes de su fallecimiento, Francesco Orlando, 
apoyarse recíprocamente, complementándose: el registro mezzano, al que - según Bruni (1990) ${ }^{7}$ - el género novelístico y el Decamerón pertenecen, y donde los hechos y los asuntos comunes ocupan el entero espacio textual, rechaza la esfera del trágico, por lo que dice Auerbach que, en la medida en que -como asevera el Boccaccio de las Genealogie- se hace inaplicable en él la exégesis alegórica, es el único vehículo capaz de elevar los communia, liberándolos del mero significado literal, que es donde quedan confinados en los géneros cómicos.

Volviendo al terceto del Viaje del Parnaso, en el verso con el que define el conjunto de sus novelas: «mostrar con propiedad un desatino», Cervantes combina dos términos que expresan conceptos aparentemente contrarios. Si nos limitamos a la colección de novelas, donde aparece dos veces, el sustantivo desatino es usado en otros tantos discursos de los personajes para indicar, en El amante liberal, el acto insensato de renegar de su propia fe cristiana por parte de Mahamut ${ }^{8}$, o bien el no menos desacertado de concederse virgen al hombre que la deshonra por parte de Teodosia, en Las dos doncellas ${ }^{9}$. Así, si pudiéramos considerar las otras 36 ocurrencias del sustantivo: desde la Galatea, donde — por ejemplo-desatino sugiere la insensatez del gesto suicida de Lenio, llevado a ello por la «fuerza de la pasión amorosa» ${ }^{10}$, hasta el Quijote, donde nuestro término aparece a menudo, aunque no exclusivamente, para deplorar el loco comportamiento del noble protagonista $^{11}$; teniendo en cuenta éstas y las restantes ocurrencias - repito- quedaría confirmado que con desatino se debe entender «un acto o un dicho determinado por la falta de discernimiento o de juicio por parte de quien lo cumple o lo pronuncia, quien, haciendo o diciendo así, quebranta una serie de normas dictadas, según

al contraponer a la «partialité» de Bajtin «l’objectivité qui risque de rendre Auerbach [...] moins intégralement et sincèrement objectif face à certes auteurs, trés éloignés les uns des autres non seulement dans le temps?», y después de haber nombrado a un grupo de autores (Petronio, Chrétien de Troyes, Boccaccio, Rabelais, Cervantes, Molière, Voltaire) «sur la base d'une vague analogie de traitement dans Mimésis», añadía que «l’on relève à première vue que chez tous abondent des éléments badins, comiques ou ironiques, à l'exception de Chrétien de Troyes» (Orlando 2009: 260). Sobre los motivos más profundos de la actidud de Auerbach, remito a la explicación propuesta por Orlando (2009: 261-262).

7 Léanse del mismo autor las consideraciones sobre la «applicabilità al Decameron [...] delle categorie elaborate dalle Genealogie per la difesa della poesia» (Bruni 1990: 47 y ss.).

$8 \quad$ Véase Cervantes (2013: 126): «el desatino que he hecho en vestirme este hábito», dice Mahamut a Ricardo.

$9 \quad$ Véase Cervantes (2013: 448): «me entregué en su poder a hurto de mis padres, sin tener otro testigo de mi desatino que un paje de Marco Antonio».

10 Véase Cervantes (1914: II, 268): «Elicio y Erastro començaron a subir la peña para estorvarle [a Lenio] que no hiziese algún otro desatino que le costase más caro» (l.VI).

11 Sobre el significado de desatino en el pasaje del Viaje del Parnaso han escrito Riley (1971: 44-46), Forcione (1984: 12-13) y Close (2007: 34). Sorprende que en el volumen IV de la Gran Enciclopedia Cervantina no haya una entrada dedicada a un término tan significativo en la poética de Cervantes. 
los casos, por códigos éticos, religiosos, sociales o, simplemente, racionales». En suma, como también lo define un antiguo y autorizado diccionario ${ }^{12}$, desatino denota el error, en sus diferentes tipologías. Pero, dado que, como se recordará, el error o el defecto $(\alpha ́ \alpha \alpha \rho \tau \eta \mu \alpha)$, en cuanto fuente del ridículo, es lo que en la Poética aristotélica mejor define al género cómico por excelencia, la comedia ${ }^{13}$, se deduce que Cervantes con el vocablo aquí brevemente comentado está de hecho confirmando el vínculo del género novelístico, al que dicho vocablo se refiere, con la tradición cómica a la que la novela se remonta.

Pero ¿qué entiende Cervantes, cuando en el mismo verso afirma que la novedad de su colección consiste en el tratar la novela, en cuanto género cómico, «con propiedad»? Afortunadamente, puedo salir del paso con la máxima prontitud, porque en algunas páginas del importante libro de Anthony Close titulado Cervantes y la mentalidad cómica de su tiempo, fruto de una entera vida de estudios dedicados al sumo narrador español, su autor planteó el mismo interrogativo $\mathrm{y}$, a partir de algunos pasajes tomados de diversas obras cervantinas, dedujo que el significado del sustantivo 'propiedad' de nuestro terceto resultaba de la combinación de dos conceptos: el de decoro, por un lado, y el de habilidad o perfección artística, por otro, por lo que en los versos del Viaje del Parnaso, refiriéndose a su colección de novelas, Cervantes expresaría la idea —así lo reafirma con extrema síntesis el añorado estudioso británico- de una «comicidad realizada con arte» (Close 2007: 38).

Y sin embargo, no creo que esta conclusión, por más que innegable, sea suficiente para agotar el discurso sobre la operación que Cervantes cumple en relación con el género novelístico. En las mismas páginas de Close, a las que acabo de recurrir, en al menos un par de puntos, desgraciadamente muy concisos, parece vislumbrarse la conciencia de que la naturaleza de tal operación va más allá de la ya de por sí esencial conversión artística de la novela en el ámbito hispánico, para obtener un resultado más ambicioso todavía, como cuando, precisamente con referencia al libro de novelas, nos tropezamos con una alusión a «una extravagante anormalidad en su ficción cómica» (2007: 152) o, con más aguda conciencia de la novedad, en la aserción: «tanto lo cómico como lo épico se acercan al borde de un mismo abismo (el disparate, el desatino) y son rescatados del desastre por una cuerda de seguridad parecida» (2007: 40). He aquí, según mi parecer, la clave de toda la cuestión: en las novelas cervantinas encontramos realizada una inédita

Diccionario de Autoridades (1732): «Vale también locura, disparate, despropósito u error».

13 En la Poética de Aristóteles, al principio del cap. V, se lee: «La comedia es, como hemos dicho, imitación de hombres inferiores, pero no en toda la extensión del vicio sino que lo risible es parte de lo feo. Pues lo risible es un defecto $(\alpha \dot{\alpha} \mu \rho \tau \eta \mu \alpha)$ y una fealdad que no causa dolor ni ruina» (Aristóteles 1974: 1449a). Se sabe que Aristóteles utiliza el mismo término ( $\alpha \alpha \alpha \rho \tau \eta \mu \alpha$, defecto) con el que explicará en el cap. XIII la causa fundamental del cambio o pase de la acción trágica. 
proximidad — claro, no todavía la coincidencia— de los dos registros mantenidos diferenciados por la tradición literaria, el alto y el bajo, el cómico y el épico; una proximidad que hay que entender no tanto como la contigüidad de registros hecha posible por la adopción de un nivel mezzano - la decameroniana «totalità rappresentativa: enciclopedia degli stili, ma anche enciclopedia del reale» (Borsellino 1979: 35), para valernos de una útil formulación sintética一, sino como «penetración en lo problemático o en lo trágico» — por decirlo como Auerbach—obtenida gracias a una representación de la realidad que, no obstante, identifica su objeto en los communia, los hechos y los asuntos comunes, o — de manera todavía más significativa - en los desatinos, esos despropósitos o errores que desde siempre constituían el objeto privilegiado de la tradición literaria cómica.

Tal conclusión nos ayuda, quizás, a comprender mejor el sentido que hay que dar a la vinculante promesa de ejemplaridad que, junto con la mencionada reivindicación de prioridad y de originalidad, es el objeto de la segunda parte del prólogo del que hemos partido. Porque ya desde el título de Novelas ejemplares, la iunctura de calificativo y sustantivo, en la España en tiempos de la publicación de la colección, debió de parecer una especie de contrasentido, ya que la reputación de licenciosidad por la que estaba marcada la tradición novelística boccacciana mal se avenía con la finalidad moral que el escritor español pretendía conferir al género del que se proclamaba inventor en castellano ${ }^{14}$ :

Heles dado el nombre de ejemplares —así Cervantes justifica el calificativo en el prólogo, dirigiéndose siempre al «lector amable»—y si bien lo miras, no hay ninguna [novela] de quien no se pueda sacar algún ejemplo provechoso; y si no fuera por no alargar este sujeto, quizá te mostrare el sabroso y honesto fruto que se podría sacar, así de todas juntas, como de cada una de por sí [...]. Una cosa me atreveré a decirte —insiste el autor unas líneas más adelante— que si por algún modo alcanzara que la lección destas Novelas pudiera inducir a quien las leyera a algún mal deseo o pensamiento, antes me cortara la mano con que las escribí que sacarlas en público (Cervantes 2001: 18-19) ${ }^{15}$.

En efecto, las cosas son mucho más complejas, y así nos lo parecerán si consideramos que, en torno a la mitad del siglo xvı, en Italia «la novella si è fatta [...] crocevia di esperienze narrative che ne hanno cambiato e adattato il volto a diverse esigenze» $\mathrm{y}$, sobre todo, que los novelistas italianos ya habían expresado por entonces «una preoccupazione di $[\ldots]$ ordine morale» a la que — se

14 Sin embargo, el problema ya estaba presente en las recopilaciones italianas de novelas del último cuarto del siglo xvi; para ello véase Blecua (1989: 73).

15 Sobre la ejemplaridad de las novelas cervantinas existe una bibliografía muy abundante; para un primer acercamiento a la cuestión, véase el «Prólogo» de García López (Cervantes 2001: LXXXIXxcv), donde el lector encontrará también algunas importantes referencias bibliográficas.

Edad de Oro, XXXIII (2014), pp. 35-51, ISSN: 0212-0429 
ha dicho- «si affiancano le motivazioni di prestigio» (Bragantini 1987: 233 y 227). El hecho es que en la citada certificación proemial de ejemplaridad, la lectura de las novelas cervantinas nos incita a reconocer no tanto una verdad moral didácticamente transmisible, aunque el compromiso ético del autor es incontestable, ni sólo la excepcional consistencia o eficacia estética de los relatos, por mucho que la habilidad o perfección artística afecte fundamentalmente a todos los niveles de la narración, desde el estilo a la caracterización de los personajes, a la perspectiva narrativa, etc.; sino que induce a advertir, aun en su fidelidad al género cómico elegido, si bien radicalmente recodificado, una problematización de lo real —no encuentro otra expresión más adecuada—, a la que el autor mismo parece querer aludir cuando, en sus líneas conclusivas del mismo prólogo, asevera de sus novelas que «algún misterio tienen escondido que las levanta» (Cervantes 2001: 20).

En el espacio del que todavía dispongo, quisiera pasar de la teoría a la praxis, tratando de mostrar brevemente cómo la radical recodificación del género novelístico realizado por Cervantes en relación con el modelo boccacciano consiste en la que acabo de definir, sobre la base de Auerbach, como «una problematización de lo real», o sea, en la «penetración en lo problemático e [incluso] en lo trágico», a partir de temas que la tradición novelística y, en particular, el modelo boccacciano de la novela solía desarrollar bajo el signo de la comicidad. Pues bien, en esta tradición novelística, ¿qué hay más cómico que el personaje del marido celoso, del marido que, aun estando obsesionado por la enfermedad de los celos, acaba siendo mala y ridículamente escarnecido?

En el Decamerón, las novelas sobre los maridos celosos se concentran en la VII jornada, la que — como se recordará— tiene lugar bajo el mandato de Dioneo, y durante la cual «si ragiona delle beffe», que —reza la rúbrica puesta al comienzo de la jornada — «o per amore o per salvamento di loro le donne hanno già fatte a’ suoi mariti, senza esserne avveduti o sì» (Boccaccio 2013: 1073). Como ha resumido Cesare Segre, autor de un estudio «de tipo formalista-semiológico» sobre la VII jornada del Decamerón:

si tratta di un tema diffusissimo nel folclore mondiale (e non solo nel folclore, beninteso): cioè quello del triangolo amoroso, nel tipo M-D-A (marito-donna-amante della donna) e con uno sviluppo fisso: la donna, mediante una beffa al marito, riesce ad attuare, mascherare e in genere continuare il suo tradimento. Non per nulla la narrazione ha come ambiente la Valle delle Donne (Segre 1974: 117).

En el marco, pues, del triángulo amoroso que opera en las novelas y de las burlas como «tema da ragionare» común a toda la jornada, en tres de las diez novelas los celos se convierten en el tema fundamental de las intrigas entre mujer y marido. Es más, en las tres novelas mencionadas son precisamente los celos 
del marido los que originan la traición de la mujer, y, en consecuencia, «le beffe [attuate per ordire o coprire il tradimento] sono qui la rappresaglia, quasi sempre approvata dai favolatori e dall'autore, contro atteggiamenti contrari all'ideale umano del Boccaccio» (1974: 120). No hay duda de que en nuestras tres novelas lo que determina la contraposición, a la que se refiere el propio Dioneo, entre las «savie mogli» y los «sciocchi mariti» (Boccaccio 2013: 1165), son los celos de estos últimos, quienes, por otra parte, a menudo temen ser traicionados por sus esposas sin razón alguna.

En la cuarta novela de la jornada, en efecto, Laureta cuenta que el rico aretino Tofano tenía por esposa a una bellísima mujer, Ghita, «della quale egli senza saper perché presto divenne geloso» (Boccaccio 2013: 1100). A tal actitud del marido, Ghita reacciona, primero, decidiendo buscarse un amante sólo para vengarse de los injustificados celos de Tofano, y, luego, mostrándose dispuesta a actuar ante la trampa que él le ha tendido. En la construcción narrativa, de todas formas, si se prescinde del joven amante, que queda completamente en el trasfondo, a los otros dos personajes que componen el triángulo erótico se les da un peso diverso, evidenciando el protagonismo de la mujer con respecto al marido. En todo caso, en la contraposición entre los dos cónyuges, la negatividad del personaje del marido es subrayada más de una vez por Laureta, o sea, por la narradora de la novela. En efecto, en contraste con el comportamiento avisado de Ghita, de la que la narradora subraya su agudeza de ingenio (2013: 1102), Tofano se comporta como un bestia, tal y como lo llama la narradora en dos ocasiones diversas: «quella bestia era pur disposto a volere che tutti gli aretini sapessero la lor vergogna, là dove niun la sapeva» (2013: 1102) y, un poco más adelante, «Tofano bestia [...] diceva come il fatto era stato e minacciavale forte» (2013: 1104).

En la novela sucesiva, la quinta de la jornada, la narradora, Fiametta, declara inmediatamente que quiere enlazar con la novela que acaban de escuchar, sosteniendo que es justo que los celosos sean castigados: «la precedente novella - afirma Fiammetta - mi tira a dover similmente ragionar d'un geloso, estimando che ciò che si fa loro dalla lor donna, e massimamente quando senza cagione ingelosiscono, essere ben fatto» (2013: 1106). Por lo que, en consecuencia —concluye Fiametta la parte introductoria de su narración-, las mujeres que se burlan de los maridos celosos deberían ser alabadas y no condenadas. El suceso, esta vez, tiene lugar en Rímini, donde un rico mercader, estando «oltre misura geloso» sin motivo de su bellísima mujer, la tenía encerrada: «E così ingelosito tanta guardia ne prendeva e sì stretta la tenea, che forse assai son di quegli che a capital pena son dannati, che non sono da' pregionieri con tanta guardia servati» (2013: 1108). De nuevo será el ingenio femenino el que permitirá a la esposa del mercader sustraerse al rígido control masculino y actuar de modo que el marido se sienta celoso con alguna razón. Desde el punto de vista narrativo, es importante observar la atenta 
distribución de los espacios interiores del edificio en el que viven los protagonistas y, en particular, la relación entre la casa de los esposos y la contigua, donde vivía Filippo, «giovane e bello e piacevole» que se convertirá en el amante de la mujer del mercader. He aquí cómo la mujer, sonriendo, se dirige al marido ya cornudo, con una comparación que suena a mordaz y despiadada: «Egli mi giova molto quando un savio uomo è da una donna semplice menato come si mena un montone per le corna in becheria: benché tu non sè savio, né fosti da quella ora in qua che tu ti lasciasti nel petto entrare il maligno spirito della gelosia senza saper perché: e tanto quanto tu sè più sciocco e più bestiale, cotanto ne diviene la gloria mia minore» (2013: 1116). Cegado por los celos, en las palabras que la mujer le dirige, el rico mercader de Rímini queda reducido por su misma estupidez a una condición de bestialidad, acabando por ser degradado al nivel de un carnero cogido por los cuernos. Un juicio que, por lo demás, es compartido por la entera compañía, ya que, tras haber terminado Fiametta el relato, todos afirman que la mujer ha obrado óptimamente, dando «quel che si convenia al bestiale uomo» (2013: 1119).

La última novela del trío, la octava de la jornada, propone de nuevo un caso de castigo del celoso y de exaltación de la sagacidad femenina. El error del protagonista masculino, el riquísimo mercader florentino Arriguccio Berlinghieri, es doble: el primero consiste en el hecho de que «sì come ancora oggi fanno tutto ' $l$ dì i mercatanti, pensò di volere ingentilire per moglie; e prese una giovane gentile donna male a lui convenientesi, il cui nome fu monna Sismonda» (2013: 1135); el segundo error fue que «egli diventò il più geloso uomo del mondo» (2013: 1135). Víctima de la traición de la mujer y, a la vez, de la burla con la que ella le disimula su traición, Arriguccio se ve sometido a la feroz invectiva de la suegra, quien lo increpa comparándolo a un perro, indigno de su noble esposa: «si vorrebbe uccidere questo can fastidioso e sconoscente, ché egli non ne fu degno d'avere una figliuola fatta come sè tu» (2013: 1143).

En suma, en las tres novelas decameronianas de la séptima jornada que presentan una temática análoga, los celos se consideran al nivel de la bestialidad, tanto que - como hemos visto- al aretino Tofano de la cuarta el texto se refiere directamente con el epíteto de bestia, mientras que al anónimo de Rímini de la quinta y al mercader Arriguccio de la octava se los compara, respectivamente, con un carnero y con un perro. A la celosa bestialidad de los maridos que, volviéndolos necios, los convierte en burlados y cornudos, se contrasta la sagacidad femenina, gracias a la cual las malmaridadas obtienen la realización del placer, que es el verdadero corazón y motor de la narración. Son relatos, por tanto, que se concentran en el montaje de la acción, por medio de la cual el deseo natural femenino se cumple y, al mismo tiempo, se ridiculizan los represivos celos maritales. 
Se recordará que, al comienzo de estas notas, dije que me vería obligado a pasar por alto el siglo «di massima proliferazione della forma novellistica», el siglo Xvi, al que me prometía volver para hacer solamente una rápida mención. Ahora bien, si consideramos la obra novelística italiana más conocida y apreciada en Europa, después del Decamerón, las quinientistas Novelas de Matteo Bandello, es para señalar con la máxima brevedad cómo, con respecto a los mencionados relatos boccaccianos, las novelas de Bandello centradas en el personaje del marido celoso no presentan cambios sustanciales. Para poner sólo dos ejemplos sacados de las 214 novelas que formaban la edición italiana publicada en 1554, los relativos al celoso caballero napolitano Angravalle (I, 5) y al anónimo celoso provenzal (II, 25), no es difícil constatar que, a pesar del incremento de los enredos de las situaciones narrativas, en ambas novelas la pasión celosa de los maridos no llega a ser objeto de ninguna profundización, ni mucho menos sufre algún proceso de problematización. En la primera de las dos novelas, en efecto, el lector es informado inmediatamente de que, tras dos años de matrimonio, Angravalle comienza a sentir celos de su mujer, Bindoccia, a quien impone el consabido régimen de aislamiento; luego, todo el relato se concentra en la doble burla que la mujer urde para realizar y disimular su traición con el joven Niceno. Ni tampoco falta la degradación en animal del marido celoso, comparado dos veces con el «montone» (Bandello 1928: 79 y 83), y una con un «sozzo cane» (1928: 87), y sobre el que pesa el siguiente y primer juicio de la mujer: «senza ragione è divenuto geloso, adesso non geloso, ma farnetico e scimonnito mi pare» (1928: 73). Precedida de una prolija reflexión sobre los celos, la breve segunda novela finaliza una vez más con el relato de la burla con la que la adúltera pone remedio al plan que el marido celoso urde para verificar la fidelidad de la mujer. Un plan que, como sentencia el narrador, es fruto de «suo sciocco pensiero» (Bandello 1911: 142), y del que él mismo será víctima, pagando con una muerte ridícula su insana pasión. Y ni siquiera, en verdad, el autor consigue juntar sólidamente el suceso narrado con el largo discurso preliminar, ya que uno de los motivos teóricos de la premisa: que los celos son el fruto del sentido de inferioridad en relación con el rival en amores, no encuentra luego confirmación en la narración, a no ser en el juicio fugaz de la mujer, según el cual los celos del marido «da altro non nasceva se non da una dappocaggine che in lui era, perché nei servigi de le donne nulla valeva» (1911: 140), pero sin que tal opinión tenga la mínima correspondencia en la representación del personaje del marido celoso.

La novela cervantina El celoso extremeño «deriva de uno de los ciclos temáticos más socorridos de la novela italiana y que siempre interesó a Cervantes», escribe García López en su comentario (Cervantes 2013: 325), aludiendo a la tradición de la novela italiana de la que he señalado la etapa fundacional 
boccacciana y la descendencia quinientista representada por Bandello ${ }^{16}$. En efecto, con El celoso extremeño nos hallamos en el punto culminante de esta tradición novelística, por lo general cómica, que adopta como núcleo temático el triángulo adulterino, y que despliega como situación narrativa la de la rigurosa y constante clausura de la mujer por parte de un marido preso de unos celos demenciales. El hecho es que, respecto a dicha tradición, la novela cervantina representa un cambio sustancial, al proponer algo muy diferente.

En la novela cervantina la pasión celosa del viejo, rico e impotente Carrizales ocupa el centro del espacio textual, por lo que es inevitable que cambie de carácter y se transforme en algo terriblemente problemático —e incluso trágico— respecto a los cómicos celos de los numerosos personajes de esa tradición novelística, de la que nuestra historia es heredera, pero que deja a sus espaldas renovándola profundamente. Protagonista desde el título, el papel del viejo marido celoso adquiere una inédita consistencia y un significado complejo que el lector nota apenas se introduce en el texto, cuando descubre que la excesiva inclinación morbosa del personaje, por una parte, preexiste a la elección del objeto amoroso y, por otra, se pone en relación con un sentimiento análogo con respecto al oro acumulado en América. Que, en resumen, en el texto se da una estrecha relación entre el universo afectivo y el universo económico, entre matrimonio y patrimonio, entre el temor celoso de perder el imaginario objeto de amor y el terror de que se le sustraiga el oro real que el viejo descubre con consternación, que no sabe cómo emplearlo:

Contemplaba Carrizales en sus barras, no por miserable, porque en algunos años que fue soldado aprendió a ser liberal, sino en lo que había de hacer dellas, a causa que tenerlas en ser era cosa infrutuosa, y tenerlas en casa, cebo para los codiciosos y despertador para los ladrones. [...] y en viniéndole este pensamiento [del matrimonio], le sobresaltaba un tan gran miedo, que así se le desbarataba y deshacía como hace a la niebla el viento, porque de su natural condición era el más celoso hombre del mundo, aun sin estar casado, pues con sólo la imaginación de serlo le comenzaban a ofender los celos, a fatigar las sospechas y a sobresaltar las imaginaciones, y esto con tanta eficacia y vehemencia, que de todo en todo propuso de no casarse (Cervantes 2013: 329-330).

Para que todo tenga sentido, es necesario que el lector de la novela aprenda a transformar ese miedo en su contrario y ver en los celos del viejo la fascinación o la envidia que él siente por el deseo del otro. No es casual, por lo tanto, que Carrizales se decida a contraer matrimonio sólo cuando, en el encuentro con Leonora, la elección del objeto resulta dictada por la lógica que opera en él del deseo mediato. Es cierto, por otra parte, considerar — como ya han propuesto algunos

16 Para un primer contacto con la rica bibliografía de El celoso extremeño, véase la «Nota bibliográfica» que el editor de las Novelas ejemplares dedica a esta novela (Cervantes 2013: 975-996). 
autores - la casa-convento como la verdadera protagonista de la narración, siempre que en el increíble sistema de absurdas y coercitivas precauciones en el que ésta consiste, se reconozca el conjunto de medidas cautelares con las que en Carrizales se expresa el temor/atracción frente al deseo de Leonora, que se presenta joven y pobre, tanto como el hombre que la ha subyugado, casándose con ella, es viejo y rico. Un poco menos joven que la malcasada, el virote sevillano Loaysa es tan rico como el viejo, pero se ve obligado a fingirse pobre porque así lo requiere la estrategia que ha ideado para entrar en la casa, no menos de lo que lo requiera la lógica que preside el significado de la historia que se narra.

En la novela cervantina, por tanto, la constelación de personajes principales que forman el tradicional triángulo erótico se lleva a cabo dando lugar a una figura muy compleja del deseo mediato, que - como es obvio- se manifiesta en su más alto grado en el celoso, pero que también acomete al amante más joven, atraído por el objeto que otros poseen y que, por último, implica también a la joven quien para afirmar su propia individualidad debe ser capaz de negarse al uno y al otro, imponiendo su propia subjetividad al mostrarse al marido tirano como un sujeto autónomo de deseo, y revelando su propia especificidad al negarse a la acción amorosa con el desidioso amante. El final se parece al de un drama: Carrizales muere, absteniéndose de la venganza que no habría limpiado su honor y a la que ya había renunciado en el momento de unirse a Leonora. Sobre ella se cierne la poco benigna suerte de pasar de la clausura de la marital casa-convento a la de un convento real, hacia el que se dirige. En cuanto a Loaysa, sólo puede estar destinado a seguir los pasos del hombre en cuyo pellejo (y lecho) había anhelado meterse; así pues, se trasladará a las Indias occidentales, como el viejo antes de serlo, lo que le dará a la estructura de la novela la misma marca de clausura que caracteriza la trama.

Las breves observaciones apuntadas son suficientes, creo, para intuir que la novela cervantina, a pesar de lo común de la temática de fondo, resulta lejana de los remotos y fundadores cuentos del Decamerón, y también de aquellos más cercanos temporalmente de Bandello, por ejemplo, si se piensa en novelas como las del celoso caballero napolitano Angravalle o en la del anónimo celoso provenzal. Al distorsionar los resultados de análogas situaciones narrativas de la tradición novelística, el misterio del singular caso del viejo Carrizales y de los dos jóvenes amantes fracasados encierra una ejemplaridad que no participa ni de una moral que tiene su baricentro en «una nuova armonia tra istinto naturale e virtù» (Baratto 1999: 59), como la que gobierna las historias del Decamerón de tema similar, ni de una preocupación de exclusivo orden moral que suele presidir las obras de los novelistas contrarreformadores. Ocupando la posición central del conjunto narrativo, el personaje del marido celoso se redime de la antigua marca ferina y se convierte en el portador de una ejemplaridad que tiene algo de heroico, porque en los celos 
se esconde el sentimiento de rebelión contra el último destino del hombre, el último doloroso baluarte de quien se resiste a la muerte como, por lo demás, también resulta de esta explícita afirmación del narrador del Persiles en la que quizás no sea erróneo reconocer la voz del mismo Cervantes:

uno de los efectos poderosos de la muerte es borrar de la memoria todas las cosas de la vida, y pues llega a hacer que no se sienta la pasión celosa, téngase por dicho que puede lo imposible (Cervantes 1979: 160),

donde los celos son, por lo tanto, la última y más fuerte resistencia con la que se manifiesta en el hombre el vínculo con la vida. Si las cosas están así, se entiende mejor lo que quería decir Cervantes en el acto de concluir el prólogo, cuando afirma enigmáticamente que sus novelas «algún misterio tienen que las levanta», tratándose de algo que operando, por así decirlo, en los pliegues del texto, contribuye a dar un grado de mayor dignidad al antiguo género novelístico.

En las pocas y densas páginas de su libro dedicadas a la novela clásica, a próposito de la recopilación cervantina, Thomas Pavel ha escrito que éstas «profundizan en la verosimilitud moral examinando la adversidad interna visible pero incomprensible, es decir, aquellas pasiones cuya naturaleza o razón de ser el protagonista nunca llegar a comprender» (Pavel 2005: 110). Los celos de Carrizales son uno de los ejemplos más clarificadores con los que se concreta tal «adversidad interna visible pero incomprensible»: él, como el personaje del enamorado voluble, junto con muchos otros protagonistas de las novelas cervantinas, representa -como sugiere el mismo Pavel- el «personaje tipo de origen susceptible de convertirse en el objeto de una trama seria» (111).

Cuando, a finales del siglo xvi y principios del siglo XVII, en Italia se entra «in un tempo di crisi (se non ancora di interruzione), della tradizione novellistica», este poner en el centro de las tramas novelísticas unos protagonistas cuyas acciones son motivadas por oscuras (en cuanto a ellos les resultan incomprensibles) hostilidades y contrariedades interiores, proyecta el género hacia nuevos y más modernos destinos; y es significativo que después de los dos grandes períodos italianos: el de la codificación de Boccaccio vinculada a la cultura ciudadana y mercantil y el de la expansión quinientista favorecida por la corte «come luogo di ricezione», esto suceda en concomitancia con el fenómeno de «rarefazione» y «lento essiccamento» del género in Italia (Mazzacurati 1999: 147, 128, 148), en uno de los grandes estados nacionales europeos, en aquella España en la que, según un gran historiador francés, en el «tiempo del Quijote», el «naufragio de un mundo y de sus valores» (Vilar 1980: 337) coexistía con su supervivencia. 
OBRAS CITADAS

AlemÁn Illán, Jesús (1988). «La traducción por Tamayo de Vargas del ‘Ars Poetica’: estudio y valoración». Criticón, 73, pp. 5-22.

(1997). «Una traducción inédita del ‘Ars Poetica’ de Horacio por Tomás Tamayo de Vargas». Criticón, 70, pp. 117-148.

Amezúa y Mayo, Agustín G. de (1956). Cervantes creador de la novela corta española. Madrid: Consejo Superior de Investigaciones Científicas, 2 vols.

Aristóteles (1974). Poética. Valentín García Yebra (trad.), edición trilingüe. Madrid: Gredos.

Auerbach, Erich (1975). Mímesis. La representación de la realidad en la literatura occidental. México: Fondo de Cultura Económica.

Bandello, Matteo (1911). Le novelle, vol. III, Giochino Brognoligo (ed.). Bari: Laterza. (1928). Le novelle, vol. I. Giochino Brognoligo (ed.). Bari: Laterza (2a ed. revisada).

BARATto, Mario (1999). Realtà e stile nel «Decameron». Roma: Editore Riuniti.

Battaglia Ricci, Lucia (2008). Boccaccio. Roma: Salerno Editrice.

Blecua, Alberto (1989). «Las Novelas ejemplares». Anthropos, 98-99, pp. 73-76.

Boccaccio, Giovanni (1998). Genealogie deorum gentilium, Vittorio Zaccaria (ed.). En Tutte le opere, Vittore Branca (ed.). «I Classici Mondadori», vols. VII-VIII, tomo I y tomo II. Milano: Mondadori.

(2013). Decameron, Amedeo Quondam, Maurizio Fiorilla y Giancarlo Alfano (eds.). Milán: BUR Classici.

Bonciani, Francesco (1972). «Lezione sopra il comporre delle novelle». En Bernard Weinberg (ed.), Trattati di poetica e retorica del Cinquecento. Bari: Laterza, III, pp. 135-165.

Borsellino, Nino (1989). La tradizione del comico. Milán: Garzanti.

BRAGANTINI, Renzo (1987). Il riso sotto il velame. La novella cinquecentesca tra l'avventura e la norma. Florencia: L. S. Olschki Editore. (2000). Vie del racconto. Dal Decameron al Brancaleone. Napoles: Liguori.

BRINK, Charles Oscar (1971). Horace on Poetry. Cambridge: Cambridge University Press.

BRUnI, Francesco (1990). Boccaccio. L'invenzione della letteratura mezzana. Bolonia: Il Mulino.

Cervantes, Miguel de (1914). La Galatea. Rudolf Schevill y Adolfo Bonilla (eds.). Madrid: Imprenta de Bernardo Rodríguez.

(1979). Los trabajos de Persiles y Segismunda. Juan Bautista Avalle-Arce (ed.). Madrid: Castalia.

(1983). Viaje del Parnaso, Miguel Herrero García (ed.). Madrid: Consejo Superior de Investigaciones Científicas.

(2013). Novelas ejemplares. Jorge García López (ed.). Madrid: Real Academia Española.

Close, Anthony (2007). Cervantes y la mentalidad cómica de su tiempo. Alcalá de Henares: Centro de Estudios Cervantinos.

Diccionario de Autoridades (1732). Ed. facsímil. Madrid: Gredos, 1969.

Forcione, Alban K. (1984). Cervantes and the Mystery of Lawlessness: A Study of El casamiento engañoso $y$ El coloquio de los perros. Princeton: Princeton University Press. 
García Berrio, Antonio (1980). Formación de la teoría literaria moderna / 2. Teoría poética del Siglo de Oro. Murcia: Universidad de Murcia.

Gran Enciclopedia Cervantina. IV: Cueva de Montesinos-Entrelazamiento (2007). Alcalá de Henares-Madrid: Centro de Estudios Cervantinos-Castalia.

Horace, (1989). Epistles. Book II and Epistle to the Pisones ('Ars Poetica'). Niall Rudd (ed.). Cambridge: Cambridge University Press.

LASPÉRAS, Jean-Michele (1987). «La traduction des oeuvres facetieuses et des nouvelles». En J.-M. Laspéras, La nouvelle en Espagne au Siècle d'Or. Montpellier: Université de Montpellier.

MAzzAcurati, Giancarlo (1999). «Dopo Boccaccio: percorsi del genere novella dal Sacchetti al Bandello», en Giancarlo Mazzacurati, All'ombra di Dioneo. Tipologie e percorsi della novella da Boccaccio a Bandello. Matteo Palumbo (ed.). Florencia: La Nuova Italia.

MenÉndez Pelayo, Marcelino (1951). Bibliografía hispano-latina clásica. Madrid: Consejo Superior de Investigaciones Científicas.

Olsen, Michel (1976). Les transformations du triangle érotique. Copenague: Akademisk Forlag.

Ordine, Nuccio (ed.) (2001), Traités sur la nouvelle à la Renaissance. Bonciani, Bargagli, Sansovino. París-Turín: J. Vrin-Nino Aragno Editore.

OrLANDO, Francesco (2009). «Code littéraire et référents chez Auerbach». En Eric Auerbach. La littérature en perspective. Paolo Tortorese (ed.). París: Presses Sorbonne Nouvelle, pp. 211-262.

PAvel, Thomas (2005). Representar la existencia. El pensamiento de la novela. Barcelona: Crítica.

RiLEy, Edward (1971). Teoría de la novela en Cervantes. Madrid: Taurus.

SEgRE, Cesare (1974). «Funzioni, opposizioni e simmetrie nella giornata VII del Decameron». En Cesare Segre, Le strutture e il tempo. Narrazione, poesia, modelli. Turín: Einaudi, pp. 117-143.

Talavera Esteso, Francisco José (1979), «Vicente Espinel, traductor de Horacio». En Estudios sobre Vicente Espinel. Málaga: Universidad de Málaga, pp. 69-101.

VALDÉs, Juan de (1982). Diálogo de la lengua. Cristina Barbolani (ed.). Madrid: Cátedra.

VALERo Moreno, Juan Miguel (2010). «Decamerón hispano: del manuscrito a la imprenta». Hàpax, 3, pp. 97-115.

VALVASSORI, Mita (2009). Libro de las ciento novelas que compuso Juan Bocacio de Certaldo. Manuscrito J-II-21 (Biblioteca de San Lorenzo del Escorial). Madrid: Universidad Complutense de Madrid.

Vega Ramos, María José (1993). «La teoría de la novella de Francisco Bonciani». En La teoría de la novella en el siglo хй. La poética neoaristotélica ante el Decameron. Salamanca: Johannes Cromberger, pp. 97-143.

VILAR, Pierre (1980). Crecimiento y desarrollo. Barcelona: Ariel. 


\section{(3) \\ DIFFICILE EST PROPRIE COMMUNIA DICERE: \\ EL GÉNERo de la NOVELLA ENTRE BocCaccio y Cervantes}

Resumen: En un terceto del Viaje del Parnaso (IV, 25-27), Cervantes, aludiendo a su recopilación de Novelas, condensa nada menos que su teoría de la novella, que resulta tanto más reveladora si leída, no solo dentro del contexto de su misma obra literaria, sino también en relación con la pasada teoría sobre la poesía (Horacio, Ars poetica, v. 128; Boccaccio, Genealogie deorum gentilium, XIV, IX, 7). De todo ello resulta la radical recodificación del género novelístico realizado por Cervantes en relación con el modelo boccacciano. En la segunda parte del trabajo, estos resultados teóricos hallan su aplicación en una breve lectura de El celoso extremeño, efectuada en conexión con la tradición novelística cómica del «marido celoso», tal como ésta se presenta en algunos textos del Decamerón y de las Novelas de Matteo Bandello.

Palabras clave: Novela corta, Novelas ejemplares, El celoso extremeño, Boccaccio, Bandello, Ars poetica, Genealogie deorum gentilium, Decamerón.

\section{DIFFICILE EST PROPRIE COMMUNIA DICERE: THE GENRE OF THE NOVELLA FROM BOCCACIO AND CERVANTES}

Aвstract: In a tercet of his Viaje del Parnaso (IV, 25-27), Cervantes, mentioning his collection of Novelas, goes so far as to sum up in a nutshell his theory of the novella. This appears all the more striking if we do not confine ourselves to reading it in the context of his literary output, but connect his words to previous theories of poetry (Horace, Ars Poetica, v. 128; Boccaccio, Genealogie deorum gentilium, XIV IX 7). The result is a radical recoding of the novelistic genre created by Cervantes in relation to Boccaccio's model. In the second part of the essay, these theoretical results are applied to a quick reading of El celoso extremeño, analyzed in connection with the «jealous husband» tradition of the comic novella as it appears in some pages of the Decameron and of Matteo Bandello's Novelle. Keywords: Novella, Novelas ejemplares, El celoso extremeño, Boccaccio, Bandello, Ars poetica, Genealogie deorum gentilium, Decameron. 
Evangelina Rodríguez Cuadros (Universitat de València)

Novela cortesana, novela barroca, novela corta: de la incertidumbre al canon .9

Mita Valvassori (Universidad de Los Lagos)

El modelo narrativo del Decamerón en la Edad de Oro: una vieja historia .21

Antonio Gargano (Università degli Studi di Napoli Federico II)

«Difficile est proprie communia dicere»: el género de la novella entre

Boccaccio y Cervantes

Guillermo Carrascón (Università degli Studi di Torino)

Apuntes para un estudio de la presencia de Bandello en la

novela corta del siglo XVII

Leonardo Coppola (Università degli Studi «G. d'Annunzio» di Chieti-Pescara)

La proyección de Straparola en la novela española del Siglo de Oro desde una perspectiva editorial

Mireia Aldomì García

Didactismo, género literario y lector en Giraldi Cinzio.

María Jesús Zamora (Universidad Autónoma de Madrid)

«...En tiempo menos discreto que el de agora, aunque de hombres más sabios, se

Ilamaban a las novelas cuentos». La novela corta y el cuento en el Siglo de Oro.....109

Marcial Rubio (Università degli Studi «G. d'Annunzio» di Chieti-Pescara)

La contribución de Cervantes a la novela barroca: la ejemplaridad. .125

PIERRe Darnis (Université Bordeaux Montaigne)

La fuerza de la sangre, La ilustre fregona $y$ Las dos doncellas: ¿tres tipos

folclóricos?

María Soledad ArRedondo (Universidad Complutense de Madrid)

De La gitanilla $a$ La sabia Flora malsabidilla. El género, el personaje

y el matrimonio

Antonella Gallo (Università degli Studi di Verona)

Fabulaciones en equívocos burlescos: la Chrónica del monstro imaginado (1615)

de Alonso de Ledesma y novela corta barroca

David GonZález Ramírez (Universidad de Málaga)

El filósofo del aldea (1625) de Baltasar Mateo Velázquez: recepción textual

e hipótesis autorial.

Jonathan BRAdBury (University of Exeter)

La narrativa breve en la miscelánea del siglo XVII 
Cristina Castillo Martínez (Universidad de Jaén)

«La fuente del desengaño»: de las Noches de invierno de Eslava a la Tercera

Diana de Tejeda.

María Zerari (Université Paris-Sorbonne, CLEA)

Furor in fabula: La cruel aragonesa de Castillo Solórzano (o de la dama monstruo).. 241

Giulia Giorgi (Università degli Studi di Ferrara)

Alonso de Castillo Solórzano reescritor de sí mismo: algunas notas sobre los

Escarmientos de amor moralizados y el Lisardo enamorado .257

Angela Fabris (Alpen-Adria-Universität Klagenfurt)

El diálogo con el público y los espacios reales y de maravilla en

Casos prodigiosos y cueva encantada de Juan de Piña .267

María Rocío LePe García (IES San Sebastián, Huelva)

La traducción inglesa de Hipólito y Aminta: una adaptación

con fines comerciales 281

Andrea Bresadola (Università degli Studi di Udine)

La novela española en la Italia del siglo XVII: el caso de Il Feniso

de Francisco de Quintana

José Teruel (Universidad Autónoma de Madrid)

El triunfo del Desengaño. Marco y desengaño postrero de la Parte segunda

del Sarao y entretenimiento honesto, de María de Zayas

Nieves Romero-Díaz (Mount Holyoke College)

Lecturas alternativas en la Novela del fin bueno en mal principio

de doña Ana Francisca Abarca de Bolea.

Shifra Armon (University of Florida)

Compromiso y distanciamiento en La Venus de Ferrara

de Mariana de Carvajal Saavedra

Mechthild Albert (Rheinische Friedrich-Wilhelms-Universität Bonn)

Las "noches": un subgénero novelístico en perspectiva comparada.... .365

Fernando Copello Jouanchin (Université du Maine, Le Mans)

El mueble en la novela corta del Siglo de Oro: algunas reflexiones

en torno a la cama

Ilaria Resta (Università del Salento):

De la novella al entremés pasando por la novela corta: reescrituras del cuento

La gara delle tre mogli del Cieco di Ferrara. 


\section{EDAD DE ORO}

Revista de Filología Hispánica XXXIII

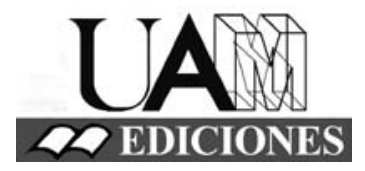




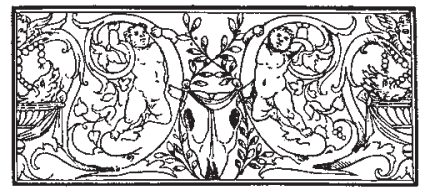

\section{Edad de Oro. Revista de Filología Hispánica}

ISSN: 0212-0429

Dirección:

Teodosio Fernández

Secretaría y edición:

José Ramón Trujillo

Coordinador del volumen XXXIII:

Rafael Bonilla Cerezo

Comité científico internacional:

Carlos Alvar (Univ. de Ginebra)

Ignacio Arellano (Univ. de Navarra)

Javier Blasco (Univ. de Valladolid)

Alberto Blecua (UAB)

Jean Canavaggio (Univ. de París X)

Laura Dolfi (Univ. de Turín)

Aurora Egido (Univ. de Zaragoza)

Víctor García de la Concha (RAE)

Luciano García Lorenzo (CSIC)

Joaquín González Cuenca (Univ. de Castilla-

La Mancha)

Agustín de La Granja (Univ. de Granada)

Begoña López Bueno (Univ. de Sevilla)

Michel Moner (Univ. de Toulouse III)

Joan Oleza (Univ. de Valencia)

Alfonso Rey (Univ. de Santiago)

Lina Rodríguez Cacho (Univ. de Salamanca)

Leonardo Romero Tobar (Univ. de Zaragoza)

Aldo Ruffinatto (Univ. de Turín)

Lía Schwartz (City University of New York)
Redacción y admisión de originales:

Teodosio Fernández

Edad de Oro

Departamento de Filología Española

Universidad Autónoma de Madrid

28049 Madrid (España)

Tfno.: +0034 914974090

correo: teodosio.fernandez@uam.es

Distribución, suscripción y venta:

Servicio de Publicaciones de la UAM

Universidad Autónoma de Madrid

28049 Madrid (España)

Intercambio de publicaciones:

Biblioteca de la Facultad de Filosofía y

Letras (UAM)

Universidad Autónoma de Madrid

28049 Madrid (España)

Han colaborado en este volumen:

Departamento de Filología Española (UAM)

Facultad de Filosofía y Letras (UAM)

Proyecto I+D FFI2013-41264-P La novela

corta del siglo XVII: estudio y edición (y II)

Edad de Oro se recoge en las siguientes bases de datos: SCOPUS, MLA Database, HLAS, Latindex, PIO-Periodical Content Index, ISOC, Dialnet, MIAR, ERIH, DICE, Sumaris CBUC, Ulrich's. Se encuentra evaluada en CIRC: A; INRECH: primer cuartil, posición 6 de 50; MIAR difusión ICDS live: 9.977; SCImago Journal \& Country Rank: H Index 2, SJR 0,101, Q4; RESH índice de impacto: 0.162; ERIH: A INT1; Carhus Plus+: B. 